\title{
Anticipating and managing coagulopathy and thrombotic manifestations of severe COVID-19
}

\author{
Lucas C. Godoy MD, Ewan C. Goligher MD PhD, Patrick R. Lawler MD MPH, Arthur S. Slutsky MD MSc, \\ Ryan Zarychanski MD MSc
}

Cite as: CMAJ 2020 October 5;192:E1156-61. doi: 10.1503/cmaj.201240; early-released August 17, 2020

CMAJ Podcasts: author interview at www.cmaj.ca/lookup/doi/10.1503/cmaj.201240/tab-related-content

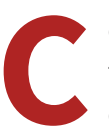

oronavirus disease 2019 (COVID-19), the disease resulting from infection with severe acute respiratory syndrome coronavirus 2 (SARS-CoV-2), exhibits a broad spectrum of manifestations and severity. Although most patients do not require admission to hospital, about $10 \%-15 \%$ of symptomatic patients are admitted, of whom about $20 \%$ receive intensive care. ${ }^{1}$ Thrombosis is a prominent clinical feature of COVID-19, and between $5 \%$ and $30 \%$ of in-hospital patients develop a clinically apparent thrombotic event. ${ }^{2-4}$ Emerging evidence suggests that endothelial injury resulting from SARS-CoV-2 cellular invasion and a subsequent dysregulated host response involving inflammatory and coagulation pathways plays a critical role in the progression of severe COVID-19. ${ }^{5}$ Macrovascular and microvascular thrombosis may contribute to organ failure, multisystem injury and death. ${ }^{6,7}$ However, the optimal prevention and treatment of thrombosis in COVID-19 remains uncertain. ${ }^{8}$ We review emerging evidence regarding COVID-19 coagulopathy (Box 1 ) and discuss current therapeutic directions and unanswered questions.

\section{How does SARS-CoV-2 lead to disordered coagulation?}

Although our understanding of the inciting mechanisms in COVID-19 coagulopathy is rapidly evolving, an emerging view suggests a cascading relationship between endothelial injury, inflammatory and immune activation, and coagulation (Figure 1A). ${ }^{9,10}$ SARS-CoV-2 enters host cells via an interaction between the viral spike protein

\section{Box 1: Evidence used in this review}

Nonsystematic literature search in MEDLINE, manual search for online published papers in the following journals: Annals of Internal Medicine, Blood, Canadian Journal of Cardiology, CMAJ, Circulation, European Heart Journal, Journal of the American College of Cardiology, Journal of the American Medical Association, Journal of Thrombosis and Hemostasis, The Lancet and New England Journal of Medicine. We have avoided citing preprint studies that have not yet undergone peer review, except for 3 articles..$^{34,63,64}$

\section{KEY POINTS}

- Coronavirus disease 2019 (COVID-19) is associated with endothelial injury and hypercoagulability.

- Common laboratory findings in COVID-19 coagulopathy include increased D-dimer and fibrinogen levels and prolongation of the activated partial thromboplastin time.

- Both venous and arterial thrombotic complications may occur with increased frequency in COVID-19 as compared with other causes of respiratory failure.

- Thromboprophylactic dose anticoagulation is broadly recommended in patients with COVID-19; clinical trials are ongoing to evaluate whether higher-dose anticoagulation confers benefit.

and the angiotensin-converting enzyme 2 (ACE2) receptor expressed in numerous organs and tissues, including pulmonary alveolar type 2 epithelial cells (which produce surfactant), the brain, heart, kidney and endothelium. ${ }^{11,12}$ ACE2 normally degrades angiotensin II, and SARS-CoV-2-mediated downregulation of ACE2 may lead to accumulation of angiotensin II, which may contribute to a procoagulant state..$^{13}$ Injury to the endothelium initiated by SARSCoV-2 entry into these cells is thought to play a key role, and likely explains the pathologic evidence of diffuse endotheliitis in multiple organs, including lungs, kidneys, heart and intestines. ${ }^{5}$ The endotheliopathy may lead to an inflammatory host response characterized by excessive immune activation and cytokine storm, which promotes hypercoagulability and thrombosis. ${ }^{14,15}$ Macrophage activation, tissue factor expression and an associated inflammatory cascade (including through interleukin-6 signalling) are hallmarks of severe SARS-CoV-2 infection. ${ }^{8,10}$

Given the inextricable links between coagulation and inflammation, D-dimer, fibrinogen and inflammatory cytokines are correlated in COVID-19 disease. ${ }^{16}$ SARS-CoV-2 activates complement pathways, further promoting endothelial cell injury, platelet activation and thrombosis. ${ }^{17}$ Inhibition of inflammatory mediators in the complement pathway in animal models of coronavirus infection, particularly the C3a and C5a, may lead to lower levels of cytokines, lower viral load and reduced pulmonary injury. ${ }^{18} \mathrm{Apart}$ from direct endothelial injury, complement activation may result 

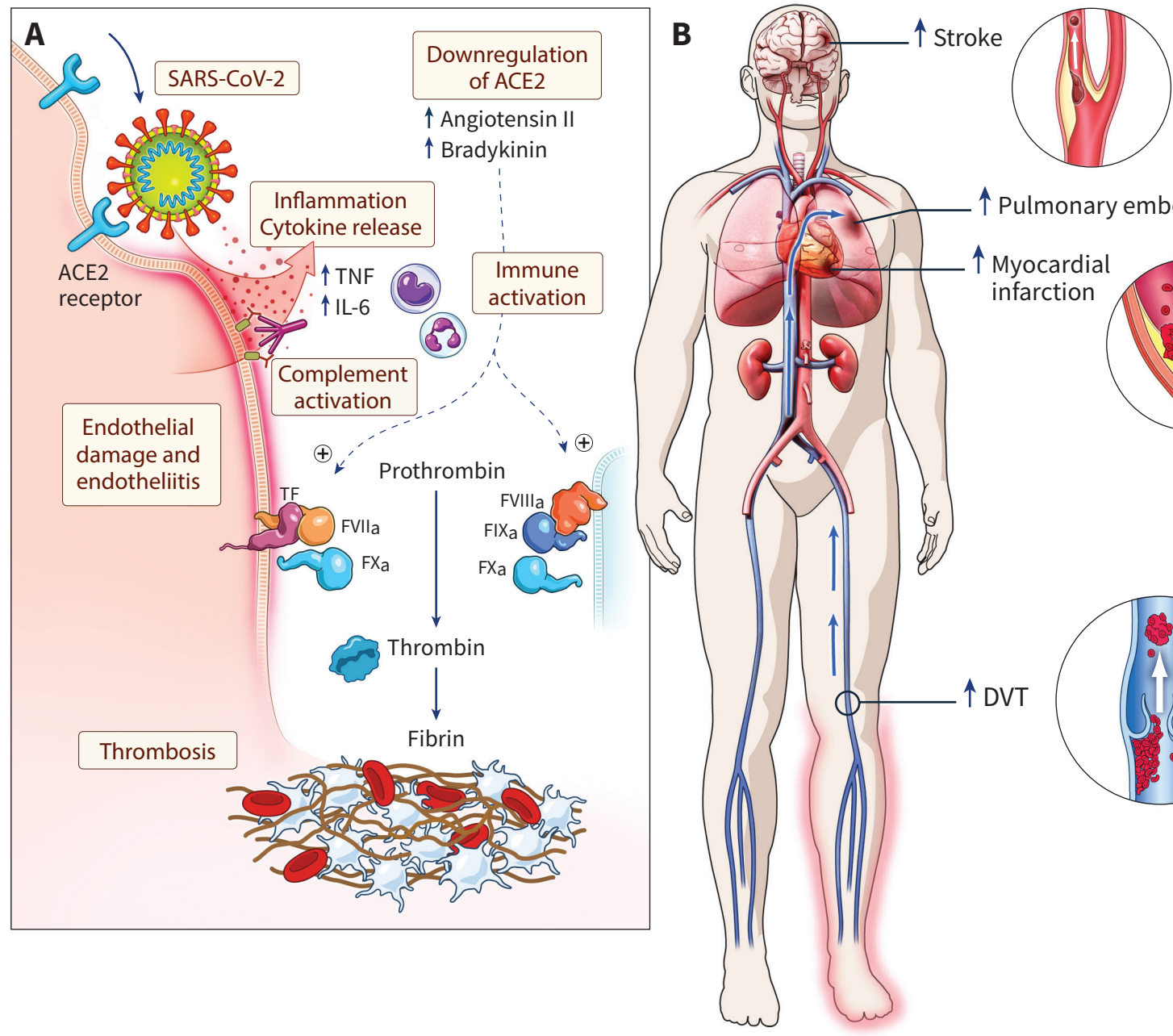

Pulmonary embolism/thrombosis

Myocardial
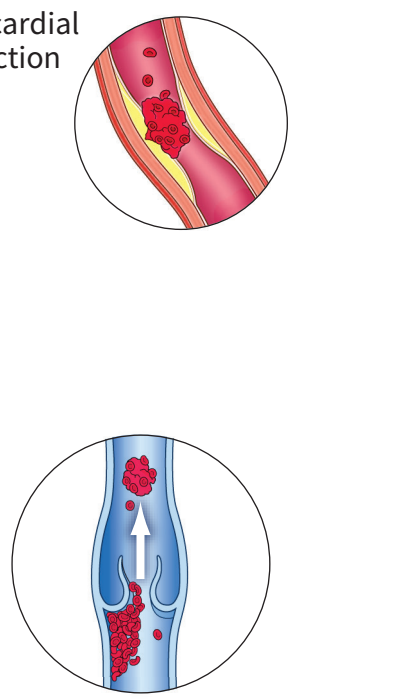

Figure 1: Possible mechanisms for thrombosis in coronavirus disease 2019 (COVID-19) and clinical consequences. (A) Injury to the endothelium initiated by severe acute respiratory syndrome coronavirus 2 (SARS-CoV-2) entry into cells via the angiotensin-converting enzyme 2 (ACE2) receptor is thought to lead to diffuse endotheliitis. The endothelial damage may result in an inflammatory host response characterized by excessive immune activation and cytokine storm, which promotes hypercoagulability and thrombosis. (B) Possible venous and arterial thrombotic complications associated with COVID19. Note: DVT = deep vein thrombosis, FVIIa = factor VIIA, IL-6 = interleukin 6, PE = pulmonary embolism, TF = tissue factor, TNF = tumour necrosis factor a. Original illustration by freelance medical illustrator Gail Rudakevich.

in thrombotic microangiopathy by inducing tissue factor expression, secretion of von Willebrand factor, and secretion and activation of factor V. ${ }^{19,20}$ Antiphospholipid antibodies and lupus anticoagulant antibodies have also been detected in some patients with COVID-19 and may contribute to the occurrence of thrombotic events, although the prevalence and clinical significance of these antibodies remain uncertain. ${ }^{21-23}$

\section{What are the potential clinical manifestations of disordered coagulation in COVID-19?}

\section{Venous thrombotic events}

Venous thrombotic events appear to occur frequently in patients with COVID-1924,25 (Figure 1B). In a case series of 107 consecutive patients with COVID-19 admitted to an intensive care unit (ICU) in France, 20\% developed venous thromboembolism (VTE) despite standard pharmacologic thromboprophylaxis (and, in 2 patients, full-dose anticoagulation). ${ }^{26}$ When compared with historical controls (including patients with respiratory failure due to influenza), patients with COVID-19 were at least twofold more likely to develop VTE during the same length of followup. ${ }^{26}$ In a separate propensity-matched cohort from France, patients with COVID-19 with acute respiratory distress syndrome were 6 times more likely to develop pulmonary embolism compared with patients with acute respiratory distress syndrome from other causes. ${ }^{23}$ Identifying markers of elevated thrombotic risk and possible impending thrombotic complications may support clinicians in anticipating such complications. Studies have highlighted biomarkers and illness severity as risk markers of elevated thrombotic risk. For example, in the Netherlands, among 198 patients in hospital with COVID-19, in whom 17\% received a diagnosis of VTE, an increased neutrophil-to-lymphocyte ratio and $\mathrm{D}$-dimer were independently associated with higher incidence of VTE, which, in turn, was associated with a 2.4-fold increased risk of death. ${ }^{27}$ By contrast, traditional clinical risk factors, such as obesity and previous thrombotic events, were not 
associated with a higher incidence of VTE ${ }^{27}$ In the United States, a multicentre observational study of 400 in-hospital patients with COVID-19 (144 admitted to the ICU) observed a $4.8 \%$ rate of radiographically confirmed venous thrombotic events and a $9.5 \%$ rate of overall thrombotic events occurring during the hospital stay. ${ }^{4}$ In this series, D-dimer $>2500 \mathrm{ng} / \mathrm{mL}$, platelet count $>45010^{9} / \mathrm{L}, \mathrm{C}$-reactive protein $>100 \mathrm{mg} / \mathrm{L}$ and erythrocyte sedimentation rate $>40 \mathrm{~mm} / \mathrm{h}$ were all independently associated with a higher likelihood of developing a thrombotic event during the stay in hospital. ${ }^{4}$ As is the case in most studies on prevalence of venous thrombotic events in COVID-19, this study is limited by the fact that it was observational and did not have a systematic protocol to screen for these events universally.

The frequency of identified thrombosis in patients with COVID-19 is appreciably higher than that reported in patients with other critical illness. ${ }^{28}$ When compared with patients with community-acquired bacterial pneumonia, patients with COVID19 had higher D-dimer levels and lower C-reactive protein levels at the time of hospital admission. ${ }^{29}$ In an autopsy series from Germany, bilateral deep venous thrombosis was detected in 7 of 12 patients with COVID-19, and massive pulmonary embolism was the direct cause of death in 4 of these patients. ${ }^{30}$ Venous thrombosis resulting in regional defects in pulmonary perfusion, together with endothelial dysfunction and impaired hypoxic pulmonary vasoconstriction, may also account for the severe hypoxemia observed in some patients with normal or near-normal respiratory system compliance. ${ }^{31}$

\section{Arterial thrombotic events}

An elevated risk of arterial thrombotic events also appears to be an important feature of COVID-19. In a cohort of 214 patients (mean age $53 \mathrm{yr}, 41 \%$ male) with COVID-19 from Wuhan, China, stroke occurred in 6 patients. ${ }^{32}$ Stroke was also reported in a case series of 5 patients aged between 33 and 49 years, in New York City. ${ }^{33}$ Small vessel in situ stroke, embolic stroke and large vessel in situ occlusions are possible mechanisms for stroke in patients with COVID-19. ${ }^{34}$

Cardiac injury (defined as serum high-sensitivity troponin above the 99th percentile of the upper limit of normal) has been shown to be common in patients with COVID-19 and associated with a markedly poorer prognosis. ${ }^{35,36}$ Among 416 patients admitted to hospital with COVID-19, about $20 \%$ had cardiac injury. ${ }^{35}$ Cardiac injury was associated with an increased risk of complications, including acute kidney injury, coagulation disorders and death (the risk for the latter being 3.4-fold higher in patients with cardiac injury than in those without it). ${ }^{35}$ The cardiac complications of COVID-19 may relate to high ACE2 expression in cardiac cells, including cardiomyocytes, fibroblasts and coronary endothelial cells, ${ }^{37}$ facilitating entry of SARS-CoV-2 into these cell types. Cardiac injury may result from microcirculatory or macrovascular coronary thrombosis (myocardial infarction), demand ischemia, stress cardiomyopathy, myocarditis and right heart strain, among other causes; ${ }^{38}$ many of these causes have potential links with hypercoagulability. Hypercoagulability in patients with COVID-19 may also play a role in the development of acute kidney injury, ${ }^{39,40}$ and acute limb and mesenteric ischemia, which have been reported. ${ }^{41,42}$

\section{Microcirculatory thrombosis}

Disseminated intravascular coagulation has been reported to be associated with severe COVID-19. In a cohort of 183 consecutive patients admitted to hospital with COVID-19, 11.5\% $(n=21)$ died, $42.6 \%(n=78)$ were discharged alive and $45.9 \%(n=84)$ were still in hospital on the last day of follow-up. A total of $71 \%(n=15)$ of the deceased patients met the International Society on Thrombosis and Hemostasis diagnostic criteria for disseminated intravascular coagulation compared with only 1 patient $(0.6 \%)$ among those discharged alive, ${ }^{2}$ but the small sample size and the fact that many patients were still in hospital at the end of the study period may limit the generalizability of the findings. ${ }^{2}$ Bleeding events in patients with COVID-19 appear uncommon, but when they occur they are likely related to consumptive coagulopathy. ${ }^{43,44}$

Intravascular coagulation may occur systemically but may be particularly pronounced, or perhaps consequential, in the pulmonary vasculature. ${ }^{6}$ The heterogeneous rates of deep venous thrombosis observed so far in patients with COVID-19 $9^{30,45,46}$ may suggest that some of the thrombotic events observed in the lungs may be caused by in situ pulmonary thrombosis rather than pulmonary embolism, which deserves further study. ${ }^{47}$ Compared with patients who died from influenza A H1N1 pneumonia in the 2009 pandemic, alveolar capillary microthrombi have been reported to be 9 times more prevalent in lungs from patients with COVID-19 who died with respiratory failure. ${ }^{48}$ ADAMTS-13 (a disintegrin and metalloprotease with thrombospondin type motifs, member 13 ) is responsible for cleaving the highly thrombogenic large multimers of the von Willebrand factor, and its deficiency may lead to thrombotic thrombocytopenic purpura, a prothrombotic condition. ${ }^{49}$ Whether reductions in ADAMTS-13 comprise an important mediator in microcirculatory dysfunction, and a contributor to organ dysfunction in COVID-19, as has been shown in septic shock, remains to be clarified..$^{50}$

\section{What biomarkers can inform the diagnosis of coagulopathy and potential treatments?}

Common laboratory abnormalities in COVID-19 coagulopathy include increased D-dimer concentrations and elevated fibrinogen. ${ }^{7,10}$ Less commonly, decreased fibrinogen and platelet concentrations associated with prolongation of the prothrombin time may occur and suggests the diagnosis of disseminated intravascular coagulation. ${ }^{2}$ Prolongation of the activated partial thromboplastin time may signify the presence of a lupus anticoagulant antibody, ${ }^{22}$ which may be associated with a prothrombotic state.

D-dimer may identify patients with COVID-19 who are at risk for thrombosis, and this marker has been proposed as a guide for clinical decision-making with respect to thromboprophylaxis. In a study of 1099 patients with COVID-19 from Wuhan, China, 46\% had a baseline D-dimer level $\geq 0.5 \mathrm{mg} / \mathrm{L}^{51}$ and in 3169 patients from New York City admitted to hospital with COVID-19, the median D-dimer at admission was elevated $(438 \mathrm{ng} / \mathrm{mL}$ [interquartile range 262-872; reference <229]). ${ }^{22}$ The International Society on Thrombosis and Hemostasis, following expert opinion and the aforementioned evidence, ${ }^{2}$ recommends measuring D-dimer in patients admitted to hospital with COVID-19 to support risk stratification. ${ }^{53}$ Elevated D-dimer at hospital admission has been associated with increased mortality. ${ }^{54-56}$ 


\section{What is the optimal antithrombotic strategy for patients with COVID-19?}

Consistent with recommendations for the care of medical patients in hospital, ${ }^{57}$ current evidence-informed recommendations emphasize the broad use of thromboprophylactic dose anticoagulation in patients admitted to hospital with COVID-19 irrespective of disease severity ${ }^{53,58}$ In the absence of clinical suspicion of VTE, there is insufficient evidence to recommend that D-dimer be used to determine whether patients with COVID-19 should receive higher-dose anticoagulation or not. A retrospective observational study from Wuhan suggested that the use of heparin (at low doses commonly used for thromboprophylaxis) versus no heparin was associated with a lower 28-day mortality in patients with elevated D-dimer or high disseminated intravascular coagulation score..$^{59}$ The study authors were not clear on which dose of heparin was used (most likely, patients in the heparin group received prophylactic doses) and it seems unlikely that many other centres would consider not using thromboprophylaxis, as was the case of the comparator arm of this study. ${ }^{59}$

Thrombotic events in patients with COVID-19 receiving heparin at standard thromboprophylactic doses have been reported, $3,23,26,27$ raising the question of whether higher doses of heparin may be beneficial for these patients. In a retrospective cohort study of 2773 patients admitted to hospital with COVID-19 in New York City, therapeutic anticoagulation (oral, subcutaneous or intravenous) was associated with increased survival. ${ }^{60} \mathrm{~A}$ longer duration of anticoagulant treatment was associated with lower mortality in patients on mechanical ventilation (adjusted hazard ratio 0.86 per day, $95 \% \mathrm{Cl} 0.82-0.89, p<0.001)$. Three percent of those receiving anticoagulants had a bleeding event, compared with $2 \%$ in those not receiving anticoagulants $(p=0.2) .{ }^{60}$ Methodological limitations of the study included immortal time bias and confounding by indication, however, which limits clinicians' ability to make inferences from the findings.

Apart from its anticoagulant effects, heparin may also provide benefit via other mechanisms, including suppressing inflammatory cytokine levels, inhibiting complement and supressing neutrophil chemotaxis and migration. ${ }^{61,62}$ Heparin has previously been shown to prevent endothelial injury by antagonizing histone and cell-free DNA and by protecting endothelial tight junctions, thus decreasing vascular leakage and pulmonary edema during sepsis. ${ }^{61}$ In COVID-19, heparin has been reported to be associated with lower levels of D-dimer, fibrinogen and the proinflammatory cytokine interleukin-6. ${ }^{16,63}$ One intriguing experimental finding is that some heparins may exert direct antiviral effects, by inducing conformational changes in the SARS-CoV-2 spike protein, thus inhibiting cellular invasion by preventing binding to ACE2. ${ }^{64}$ This antiviral effect has not yet been demonstrated in a clinical study, however.

\section{What clinical questions remain unanswered?}

Given these mechanisms and the aforementioned clinical observations, several randomized controlled trials are currently testing the hypothesis that therapeutic-dose heparin might improve outcomes in patients with COVID-19. The Antithrombotic Therapy to Ameliorate Complications of COVID-19 (ATTACC; NCT04372589) trial is a
Canadian-led international trial, enrolling non-critically ill patients admitted to hospital with COVID-19 in Canada, the United States, Brazil and Mexico. The study is randomizing patients to therapeutic heparin for 14 days versus usual care and is using a Bayesian response-adaptive randomization design to allocate treatment or control based on accumulating evidence of treatment response according to baseline D-dimer. Additional trials (NCT04362085, NCT04359277) are evaluating the effect of therapeutic anticoagulation in patients with elevated D-dimer.

Two international trials are evaluating the impact of therapeutic anticoagulation in critically ill patients requiring mechanical ventilation with or without support for organ failure. Therapeutic anticoagulation specifically for severe COVID-19 is being evaluated in the pandemic stratum of the global Randomized, Embedded, Multifactorial Adaptive Platform trial for Community-Acquired Pneumonia (REMAP-CAP; NCT02735707), and the Heparin Anticoagulation in Septic Shock trial (HALO; NCT03378466) is evaluating therapeuticdose unfractionated heparin in patients with vasodilatory shock,

\section{Box 2: Additional resources for patients and clinicians}

\section{Clinical guidance documents}

- Clinical Guidance on the Diagnosis, Prevention and Treatment of Venous Thromboembolism in Hospitalized Patients with COVID-19 (International Society of Thrombosis and Hemostasis [ISTH] $)^{72}$

- COVID-19 Treatment Guidelines from the United States National Institutes of Health ${ }^{68}$

- European Society of Cardiology Guidance for the Diagnosis and Management of CV [Cardiovascular] Disease during the COVID19 Pandemic $^{58}$

- ISTH Interim Guidance on Recognition and Management of Coagulopathy in COVID-1953

- Thromboembolism and Anticoagulant Therapy During the COVID-19 Pandemic: Interim Clinical Guidance from the Anticoagulation Forum (US) ${ }^{66}$

\section{Other online resources for clinicians}

- COVID-19 Clinical Resources from Thrombosis Canada: https://thrombosiscanada.ca/covid-19/

- COVID-19 Resource Center of the American Society of Hematology: https://hematology.org/covid-19

- ISTH Academy website (COVID-19 outbreak menu): https://academy.isth.org/

\section{Ongoing clinical trials}

- We refer readers to Bikdeli and colleagues ${ }^{67}$ for a list of ongoing clinical trials regarding COVID-19 and antithrombotic therapies. We also suggest searching the clinicaltrials.gov platform (https://clinicaltrials.gov/ct2/results?cond = COVID-19), the COVID-19 study database from the World Health Organization (https://clinicaltrials.gov/ct2/who_table), the European Clinical Trials Register (www.clinicaltrialsregister.eu/ctr-search/ search?query = covid-19) and the Global Coronavirus COVID-19 Clinical Trial Tracker (www.covid19-trials.com/).

\section{Patient resources}

- Patient resources can be found on the North American Thrombosis Forum website, which includes links to patient resources from several additional organizations: https://natfonline.org/covid-19-updates/patient-resources/. 
some of whom have severe COVID-19. The results of these trials will shed light on whether therapeutic anticoagulation with heparin is superior to standard-dose heparin for patients with moderate or severe COVID-19 disease. If it is, the potential for rapid scale-up of heparin's therapeutic application is strong, including in low- and middle-income countries, given that the drug is relatively inexpensive and widely available.

The utility of "intermediate" dose anticoagulation, the impact of antiplatelet agents ${ }^{65}$ and the benefit of postdischarge antithrombotic regimens are also relevant topics that warrant evaluation in clinical trials, some of which are planned or ongoing. Some suggest that thromboprophylaxis after hospital discharge should be considered for patients with COVID-19 who are at higher risk for venous thrombotic events (e.g., patients who have reduced mobility) or those who received mechanical ventilation. ${ }^{66} \mathrm{How}$ ever, no robust data exist to support a broad recommendation, and therefore an individualized approach to considering risk is most appropriate. ${ }^{67,68}$ Platelets play an important role in the development of thrombo-embolic events, and antiplatelet agents such as acetylsalicylic acid ${ }^{69}$ and ticagrelor ${ }^{70}$ have shown promise in reducing risk of thrombotic events among patients with respiratory infections. Very few studies have explored a possible role of antiplatelet therapy in patients with COVID-19 ${ }^{71}$ and a formal recommendation regarding its use cannot be made at this time. ${ }^{67}$

\section{Conclusion}

Thrombosis is an important feature of patients with COVID-19. Given the antithrombotic, anti-inflammatory and putative antiviral mechanisms of action of heparin, therapeutic anticoagulation offers compelling potential for benefit, but it has not yet been demonstrated that the benefits outweigh the risks. Additional resources for clinicians and patients are provided in Box 2. The results of clinical trials are urgently needed to inform the optimal care of patients with COVID-19 across the spectrum of disease severity.

\section{References}

1. Wu Z, McGoogan JM. Characteristics of and important lessons from the coronavirus disease 2019 (COVID-19) outbreak in China: summary of a report of 72314 cases from the Chinese Center for Disease Control and Prevention. JAMA 2020 Feb. 24 [Epub ahead of print]. doi: 10.1001/jama.2020.2648.

2. Tang N, Li D, Wang $X$, et al. Abnormal coagulation parameters are associated with poor prognosis in patients with novel coronavirus pneumonia. J Thromb Haemost 2020;18:844-7.

3. Klok FA, Kruip MJHA, van der Meer NJM, et al. Incidence of thrombotic complications in critically ill ICU patients with COVID-19. Thromb Res 2020;191:145-7.

4. Al-Samkari H, Karp Leaf RS, Dzik WH, et al. COVID and coagulation: bleeding and thrombotic manifestations of SARS-CoV2 Infection. Blood 2020;136:489-500.

5. Varga Z, Flammer AJ, Steiger $P$, et al. Endothelial cell infection and endotheliitis in COVID-19. Lancet 2020;395:1417-8.

6. McGonagle D, O'Donnell JS, Sharif K, et al. Immune mechanisms of pulmonary intravascular coagulopathy in COVID-19 pneumonia. The Lancet Rheumatology 2020;2:E437-45. doi: 10.1016/S2665-9913(20)30121-1.

7. Levi M, Thachil J, Iba T, et al. Coagulation abnormalities and thrombosis in patients with COVID-19. Lancet Haematol 2020;7:e438-40.

8. Cao W, Li T. COVID-19: towards understanding of pathogenesis. Cell Res 2020;30:367-9.

9. Teuwen L-A, Geldhof V, Pasut A, et al. COVID-19: the vasculature unleashed. Nat Rev Immunol 2020;20:389-91.

10. Connors JM, Levy JH. COVID-19 and its implications for thrombosis and anticoagulation. Blood 2020;135:2033-40.
11. Hoffmann M, Kleine-Weber H, Schroeder S, et al. SARS-CoV-2 cell entry depends on ACE2 and TMPRSS2 and is blocked by a clinically proven protease inhibitor. Cell 2020;181:271-80.e8.

12. Monteil V, Kwon H, Prado P, et al. Inhibition of SARS-CoV-2 infections in engineered human tissues using clinical-grade soluble human ACE2. Cell 2020;181:905-13.e7.

13. Ahmed S, Anirvan P. Reply to rheumatologists' perspective on coronavirus disease 19: Is heparin the dark horse for COVID-19? Clin Rheumatol 2020;39:2099-100.

14. Jackson SP, Darbousset R, Schoenwaelder SM. Thromboinflammation: challenges of therapeutically targeting coagulation and other host defense mechanisms. Blood 2019;133:906-18.

15. Maier CL, Truong AD, Auld SC, et al. COVID-19-associated hyperviscosity: a link between inflammation and thrombophilia? Lancet 2020;395:1758-9.

16. Ranucci M, Ballotta A, Di Dedda U, et al. The procoagulant pattern of patients with COVID-19 acute respiratory distress syndrome. J Thromb Haemost 2020;18:1747-51.

17. Magro C, Mulvey JJ, Berlin D, et al. Complement associated microvascular injury and thrombosis in the pathogenesis of severe COVID-19 infection: a report of five cases. Transl Res 2020;220:1-13.

18. Campbell CM, Kahwash R. Will complement inhibition be the new target in treating COVID-19-related systemic thrombosis? Circulation 2020;141:1739-41.

19. Noris M, Benigni A, Remuzzi G. The case of complement activation in COVID-19 multiorgan impact. Kidney Int 2020;98:314-22.

20. Keragala CB, Draxler DF, McQuilten ZK, et al. Haemostasis and innate immunity - a complementary relationship. Br J Haematol 2018;180:782-98.

21. Zhang Y, Xiao M, Zhang S, et al. Coagulopathy and antiphospholipid antibodies in patients with COVID-19. N Engl J Med 2020;382:e38.

22. Bowles L, Platton S, Yartey N, et al. Lupus anticoagulant and abnormal coagulation tests in patients with COVID-19. N Engl J Med 2020;383:288-90.

23. Helms J, Tacquard C, Severac F, et al.; CRICS TRIGGERSEP Group. (Clinical Research in Intensive Care and Sepsis Trial Group for Global Evaluation and Research in Sepsis). High risk of thrombosis in patients with severe SARS-CoV-2 infection: a multicenter prospective cohort study. Intensive Care Med 2020;46:1089-98.

24. Lodigiani C, lapichino G, Carenzo L, et al.; Humanitas COVID-19 Task Force. Venous and arterial thromboembolic complications in COVID-19 patients admitted to an academic hospital in Milan, Italy. Thromb Res 2020;191:9-14.

25. Lax SF, Skok K, Zechner P, et al. Pulmonary arterial thrombosis in COVID-19 with fatal outcome: results from a prospective, single-center, clinicopathologic case series. Ann Intern Med 2020 May 14 [Epub ahead of print]. doi: 10.7326/M20-2566.

26. Poissy J, Goutay J, Caplan M, et al.; Lille ICU Haemostasis COVID-19 Group. Pulmonary embolism in COVID-19 patients: awareness of an increased prevalence. Circulation 2020;142:184-6.

27. Middeldorp S, Coppens M, van Haaps TF, et al. Incidence of venous thromboembolism in hospitalized patients with COVID-19. J Thromb Haemost 2020 May 5 [Epub ahead of print]. doi: 10.1111/jth.14888.

28. The PROTECT Investigators for the Canadian Critical Care Trials Group and the Australian and New Zealand Intensive Care Society Clinical Trials Group; Cook D, Meade M, Guyatt G, et al. Dalteparin versus unfractionated heparin in critically ill patients. N Engl J Med 2011;364:1305-14.

29. Yu B, Li X, Chen J, et al. Evaluation of variation in D-dimer levels among COVID-19 and bacterial pneumonia: a retrospective analysis. J Thromb Thrombolysis 2020 June 10 [Epub ahead of print]. doi: 10.1007/s11239-020-02171-y.

30. Wichmann D, Sperhake J-P, Lutgehetmann M, et al. Autopsy findings and venous thromboembolism in patients with COVID-19. Ann Intern Med 2020 May 6 [Epub ahead of print]. doi: 10.7326/M20-2003.

31. Leisman DE, Deutschman CS, Legrand M. Facing COVID-19 in the ICU: vascular dysfunction, thrombosis, and dysregulated inflammation. Intensive Care Med 2020; 46:1105-8.

32. Mao L, Jin $\mathrm{H}$, Wang $\mathrm{M}$, et al. Neurologic manifestations of hospitalized patients with coronavirus disease 2019 in Wuhan, China. JAMA Neurol 2020 Apr. 10;77:1-9 [Epub ahead of print]. doi: 10.1001/jamaneurol.2020.1127.

33. Oxley TJ, Mocco J, Majidi S, et al. Large-vessel stroke as a presenting feature of COVID-19 in the young. N Engl J Med 2020;382:e60.

34. Berekashvili K, Dmytriw AA, Vulkanov V, et al. Etiologic subtypes of ischemic stroke in SARS-COV-2 virus patients. medRxiv 2020 May 15. doi: 10.1101/2020.05.03.20077206.

35. Shi S, Qin M, Shen B, et al. Association of cardiac injury with mortality in hospitalized patients with COVID-19 in Wuhan, China. JAMA Cardiol 2020;5:802-10.

36. Shi S, Qin M, Cai Y, et al. Characteristics and clinical significance of myocardial injury in patients with severe coronavirus disease 2019. Eur Heart J 2020;41:2070-9.

37. Guo J, Huang Z, Lin L, et al. Coronavirus disease 2019 (COVID-19) and cardiovascular disease: a viewpoint on the potential influence of angiotensin-converting enzyme inhibitors/angiotensin receptor blockers on onset and severity of severe acute respiratory syndrome coronavirus 2 infection. J Am Heart Assoc 2020;9:e016219. 
38. Bikdeli B, Madhavan MV, Jimenez D, et al.; Global COVID-19 Thrombosis Collaborative Group, Endorsed by the ISTH, NATF, ESVM, and the IUA, Supported by the ESC Working Group on Pulmonary Circulation and Right Ventricular Function. COVID-19 and thrombotic or thromboembolic disease: implications for prevention, antithrombotic therapy, and follow-u,p: JACC state-of-the-art review. J Am Coll Cardiol 2020;75:2950-73.

39. Batlle D, Soler MJ, Sparks MA, et al.; COVID-19 and ACE2 in Cardiovascular, Lung, and Kidney Working Group. Acute kidney injury in COVID-19: emerging evidence of a distinct pathophysiology. J Am Soc Nephrol 2020;31:1380-3.

40. Lushina N, Kuo JS, Shaikh HA. Pulmonary, cerebral, and renal thromboembolic disease associated with COVID-19 infection. Radiology 2020 Apr. 23 [Epub ahead of print]. doi: 10.1148/radiol.2020201623.

41. Bellosta R, Luzzani L, Natalini G, et al. Acute limb ischemia in patients with COVID-19 pneumonia. J Vasc Surg 2020 Apr. 29;S0741-5214(20)31080-6 [Epub ahead of print]. doi: 10.1016/j.jvs.2020.04.483.

42. Bhayana R, Som A, Li MD, et al. Abdominal imaging findings in COVID-19: preliminary observations. Radiology 2020 May 11 [Epub ahead of print]. doi: 10.1148/radiol .2020201908 .

43. Poyiadji N, Shahin G, Noujaim D, et al. COVID-19-associated acute hemorrhagic necrotizing encephalopathy: CT and MRI features. Radiology 2020;296:E119-20.

44. Lee SG, Fralick M, Sholzberg M. Coagulopathy associated with COVID-19. CMAJ 2020;192:E583.

45. Nahum J, Morichau-Beauchant T, Daviaud F, et al. Venous thrombosis among critically ill patients with coronavirus disease 2019 (COVID-19). JAMA Netw Open 2020;3:e2010478.

46. Voicu S, Bonnin P, Stépanian A, et al. High prevalence of deep vein thrombosis in mechanically ventilated COVID-19 patients. J Am Coll Cardiol 2020;76:480-2.

47. Cattaneo M, Bertinato EM, Birocchi S, et al. Pulmonary embolism or pulmonary thrombosis in COVID-19? Is the recommendation to use high-dose heparin for thromboprophylaxis hustified? Thromb Haemost 2020 Apr. 29 [Epub ahead of print]. doi: 10.1055/s-0040-1712097.

48. Ackermann M, Verleden SE, Kuehnel M, et al. Pulmonary vascular endothelialitis, thrombosis, and angiogenesis in COVID-19. N Engl J Med 2020;383:120-8.

49. Morici N, Bottiroli M, Fumagalli R, et al. Role of von Willebrand factor and ADAMTS-13 in the pathogenesis of thrombi in SARS-CoV-2 infection: time to rethink. Thromb Haemost 2020 June 23 [Epub ahead of print]. doi: 10.1055/s-0040-1713400.

50. Levi M, Scully M, Singer M. The role of ADAMTS-13 in the coagulopathy of sepsis. J Thromb Haemost 2018;16:646-51.

51. Guan W-J, Ni Z-Y, Hu Y, et al. Clinical characteristics of coronavirus disease 2019 in China. N Engl J Med 2020;382:1708-20.

52. Richardson S, Hirsch JS, Narasimhan M, et al. Presenting characteristics, comorbidities, and outcomes among 5700 patients hospitalized with COVID-19 in the New York City Area. JAMA 2020;323:2052-9.

53. Thachil J, Tang N, Gando S, et al. ISTH interim guidance on recognition and management of coagulopathy in COVID-19. J Thromb Haemost 2020;18: 1023-6.

54. Zhou F, Yu T, Du R, et al. Clinical course and risk factors for mortality of adult inpatients with COVID-19 in Wuhan, China: a retrospective cohort study. Lancet 2020;395:1054-62.
55. Zhang L, Yan X, Fan Q, et al. D-dimer levels on admission to predict in-hospital mortality in patients with COVID-19. J Thromb Haemost 2020;18:1324-9.

56. Cummings MJ, Baldwin MR, Abrams D, et al. Epidemiology, clinical course, and outcomes of critically ill adults with COVID-19 in New York City: a prospective cohort study. Lancet 2020;395:1763-70.

57. Schünemann HJ, Cushman M, Burnett AE, et al. American Society of Hematology 2018 guidelines for management of venous thromboembolism: prophylaxis for hospitalized and nonhospitalized medical patients. Blood Adv 2018;2:3198-225.

58. Bhatt DL. CABG the clear choice for patients with diabetes and multivessel disease. Lancet 2018;391:913-4.

59. Tang N, Bai H, Chen X, et al. Anticoagulant treatment is associated with decreased mortality in severe coronavirus disease 2019 patients with coagulopathy. J Thromb Haemost 2020;18:1094-9.

60. Paranjpe I, Fuster V, Lala A, et al. Association of treatment dose anticoagulation with in-hospital survival among hospitalized patients with COVID-19. J Am Coll Cardiol 2020;76:122-4.

61. Thachil J. The versatile heparin in COVID-19. J Thromb Haemost 2020;18:1020-2.

62. Liu J, Li J, Arnold K, et al. Using heparin molecules to manage COVID-2019. Res Pract Thromb Haemost 2020;4:518-23.

63. Shi C, Wang $\mathrm{C}$, Wang $\mathrm{H}$, et al. The potential of low molecular weight heparin to mitigate cytokine storm in severe COVID-19 patients: a retrospective clinical study. medRxiv 2020 Apr. 15. doi: 10.1101/2020.03.28.20046144.

64. Mycroft-West C, Su D, Elli S, et al. The 2019 coronavirus (SARS-CoV-2) surface protein (Spike) S1 Receptor Binding Domain undergoes conformational change upon heparin binding. bioRxiv 2020 Mar. 2. doi: 10.1101/2020.02.29.971093.

65. Zhou X, Li Y, Yang Q. Antiplatelet therapy after percutaneous coronary intervention in patients with COVID-19: implications from clinical features to pathologic findings. Circulation 2020;141:1736-8.

66. Barnes GD, Burnett A, Allen A, et al. Thromboembolism and anticoagulant therapy during the COVID-19 pandemic: interim clinical guidance from the anticoagulation forum. J Thromb Thrombolysis 2020;50:72-81.

67. Bikdeli B, Madhavan MV, Gupta A, et al.; Global COVID-19 Thrombosis Collaborative Group. Pharmacological agents targeting thromboinflammation in COVID-19: review and implications for future research. Thromb Haemost 2020;120:1004-24.

68. Dilsizian V, Arrighi JA, Cohen RS, et al. COCATS 4 Task Force 6: training in nuclear cardiology. J Am Coll Cardiol 2015;65:1800-9.

69. Boyle AJ, Di Gangi S, Hamid UI, et al. Aspirin therapy in patients with acute respiratory distress syndrome (ARDS) is associated with reduced intensive care unit mortality: a prospective analysis. Crit Care 2015;19:109.

70. Sexton TR, Zhang G, Macaulay TE, et al. Ticagrelor reduces thromboinflammatory markers in patients with pneumonia. JACC Basic Transl Sci 2018;3:435-49.

71. Liu X, Li Z, Liu S, et al. Potential therapeutic effects of dipyridamole in the severely ill patients with COVID-19. Acta Pharm Sin B 2020 Apr. .20 [Epub ahead of print]. doi: 10.1016/j.apsb.2020.04.008.

72. Spyropoulos AC, Levy JH, Ageno W, et al.; Subcommittee on Perioperative, Critical Care Thrombosis, Haemostasis of the Scientific, Standardization Committee of the International Society on Thrombosis, Haemostasis. Scientific and standardization committee communication: clinical guidance on the diagnosis, prevention and treatment of venous thromboembolism in hospitalized patients with COVID-19. J Thromb Haemost 2020 May 27 [Epub ahead of print]. doi: 10.1111/jth.14929.

\section{Competing interests: None declared.}

This article has been peer reviewed.

Affiliations: Peter Munk Cardiac Centre (Godoy, Lawler), University of Toronto, Toronto, Ont.; Instituto do Coracao (Godoy), Hospital das Clinicas HCFMUSP, Faculdade de Medicina, Universidade de Sao Paulo, Sao Paulo, Brazil; Interdepartmental Division of Critical Care Medicine (Goligher, Lawler, Slutsky), University of Toronto; Division of Respirology (Goligher), Department of Medicine, University Health Network; Toronto General Hospital Research Institute (Goligher, Lawler); Keenan Research Center (Slutsky), Li Ka Shing Knowledge Institute, St. Michael's Hospital, Toronto, Ont.; Max Rady Faculty of Health Sciences, Max Rady College of Medicine (Zarychanski), Department of Internal Medicine, University of Manitoba; Research Institute in Oncology and Hematology (Zarychanski), CancerCare Manitoba, Winnipeg, Man.
Contributors: All of the authors contributed to the conception and design of the work. Lucas Godoy, Ewan Goligher and Patrick Lawler contributed to the acquisition, analysis and interpretation of data. All of the authors drafted the manuscript, revised it critically for important intellectual content, gave final approval of the version to be published and agreed to be accountable for all aspects of the work. Arthur Slutsky and Ryan Zarychanski contributed equally.

Funding: All authors are investigators of the ATTACC trial (NCT04372589), which is funded by the Canadian Institutes of Health Research (CIHR), Research Manitoba, the Peter Munk Cardiac Centre and the Thistledown Foundation. Ewan Goligher is supported by an Early Career Investigator award from CIHR (AR7-162822). Arthur Slutsky holds the Keenan Chair in Medicine. Ryan Zarychanski is supported by the Lyonel G. Israels Professorship, University of Manitoba.

Correspondence to: Patrick Lawler, patrick.lawler@uhn.ca 